\title{
Studi Pembuatan Dodol dengan Konsentrasi Penambahan Salak (Salacca Zalacca) yang Berbeda
}

\author{
Iin Mardiani* \\ Pengolahan Hasil Hutan \\ Politeknik Pertanian Negeri \\ Samarinda, Samarinda \\ Iinmardiani488@gmail.com \\ *Corresponding author
}

\author{
Farida Aryani \\ Pengolahan Hasil Hutan \\ Politeknik Pertanian Negeri \\ Samarinda, Samarinda \\ ary_ani02@yahoo.com
}

\author{
Muh. Yamin \\ Pengolahan Hasil Perkebunan \\ Politeknik Pertanian Negeri \\ Samarinda, Samarinda \\ yaminpoliagro@gmail.com
}

\author{
Anis Syauqi \\ Pengolahan Hasil Perkebunan \\ Politeknik Pertanian Negeri Samarinda, Samarinda \\ anissyauqi76@gmail.com
}

\begin{abstract}
Abstrak - Salak adalah sejenis palma dengan buah yang biasa dimakan, salak termasuk buah yang mudah didapat nyaris sepanjang musim di Indonesia. Nilai ekonomis dari buah salak dapat ditingkatkan dengan mengolahnya menjadi sebuah produk seperti dodol. Dodol termasuk pangan semi basah karena mengandung kadar air $20 \%$. Metode yang digunakan dalam penelitian ini yaitu perhitungan rata-rata dengan 1 faktor yaitu varian, yang terdiri dari 3 perlakuan dan 3 kali ulangan. Perlakuan 1 yaitu menggunakan $750 \mathrm{~g}$ salak dan $250 \mathrm{~g}$ tepung beras ketan, perlakuan 2 menggunakan $500 \mathrm{~g}$ salak dan $500 \mathrm{~g}$ tepung beras ketan, dan perlakuan ke 3 menggunakan $250 \mathrm{~g}$ salak dan $750 \mathrm{~g}$ tepung beras ketan. Pada penelitian ini dilakukan pengujian kadar air, kadar abu, uji vitamin $\mathrm{C}$ dan uji organoleptik. Hasil penelitian menunjukkan bahwa didapat rata-rata dari ketiga perlakuan yang terbaik pada uji organoleptik rasa yaitu P3 (250 g salak dan tepung beras ketan $750 \mathrm{~g}$ ) sebesar 3,60 (agak suka), pada aroma yang terbaik yaitu P3 (salak $250 \mathrm{~g}$ dan tepung beras ketan $750 \mathrm{~g}$ ) sebesar 3,44 (agak suka), yang terbaik pada tekstur yaitu P3 (salak $250 \mathrm{~g}$ dan tepung beras ketan $750 \mathrm{~g}$ ) sebesar 3,51 (agak suka) dan yang terbaik pada warna yaitu P1 (salak $750 \mathrm{~g}$ dan tepung beras ketan $250 \mathrm{~g}$ ) sebesar 3,59 (agak suka). Pada kadar air terbaik pada dodol salak yaitu P3 (250 g salak dan $750 \mathrm{~g}$ tepung beras ketan) sebesar $17,75 \%$ maka sesuai dengan SNI kadar air dodol yaitu $20 \%$. Kadar abu yang terbaik pada dodol salak yaitu P3 (250 g salak dan $750 \mathrm{~g}$ tepung beras ketan) sebesar $0,56 \%$, maka sesuai dengan SNI kadar abu dodol yaitu 1,5\% dan kadar vitamin C yang terbaik yaitu pada P1 (750 g salak dan $250 \mathrm{~g}$ tepung beras ketan) sebesar 3,43 $\mathrm{mg} / 100 \mathrm{~g}$.
\end{abstract}

Kata Kunci : Dodol, Salak (Salacca zalacca), Perlakuan

\section{PENDAHULUAN}

Indonesia memiliki jenis buah-buahan yang sangat banyak. Salah satu diantaranya adalah buah salak. Daerah asal tanaman salak tidak jelas diketahui secara pasti, tetapi diperkirakan berasal dari Indonesia, Thailand, dan Malaysia. Salak (Salacca zalacca) merupakan buah tropik asli Indonesia yang banyak tersebar di seluruh kepulauan Nusantara. Tanaman salak termasuk keluarga palem-paleman (Arecacear).

Morfologi buah salak bervariasi tergantung dari varietasnya, memiliki rasa dan tekstur yang manis dan masir, mulai dari yang masih muda sampai tua, jumlah anak buah dan biji pada satu buah salak bervariasi tergantung besar kecilnya ukuran buah. Warna biji seragam, dari yang berumur muda berwana putih menuju ketua berwarna merah sampai kecoklatan. Peluang bisnis pembuatan dodol salak yang masih jarang di pasaran yang menginspirasi peneliti untuk memanfaatkan peluang pasar dengan membuat dodol dari buah salak sehingga menciptakan inovasi baru.

Dodol merupakan salah satu makanan tradisional yang mudah dijumpai di beberapa daerah di Indonesia. Dodol memiliki rasa manis gurih, berwarna cokelat, tekstur lunak, digolongkan makanan semi basah. Produk olahan dodol digemari oleh beberapa masyarakat, karena memiliki variasi rasa dan harga terjangkau. Buah salak dapat digunakan untuk menambah nilai gizi dodol.

Banyak beredar di pasaran berbagai macam dodol yang diinovasi, diantaranya dodol buah. Bahan pembuat dodol buah bermacam-macam, ada yang terbuat dari buah, tepung dan gula.

\section{METODOLOGI}

A. Waktu Dan Tempat

Penelitian ini dilaksanakan di Laboratorium Pengolahan Teknologi Hasil Perkebunan 
Politeknik Pertanian Negeri Samarinda. Penelitian ini dilaksanakan pada bulan April sampai bulan Juli 2021 meliputi, persiapan alat dan bahan, pelaksanaan penelitian, dan penyusunan.

\section{B. Alat Dan Bahan}

\section{Alat}

Adapun alat yang digunakan antara lain: alat tulis, timbangan analitik, pisau, talenan, baskom, tirisan, wajan, sutil kayu, blender, sendok, plastik, saringan, panci, kompor gas, toples, oven, erlenmeyer, tabung reaksi, gelas ukur, desikator, hot plate, tanur, spatula, pipet, gegep, cawan.

2. Bahan

Bahan yang digunakan dalam penelitian ini adalah adalah buah salak, tepung beras, tepung beras ketan, gula pasir, gula aren, air, santan, garam, vanili, kayu manis minyak goreng, Kalium Iodin, Iodin, Aquades .

Metode yang digunakan dalam penelitian ini adalah perhitungan rata-rata dengan faktor perlakuan perbandingan komposisi antara salak dan tepung beras ketan yang dapat dilihat pada tabel 3. Dengan 3 perlakuan dan 3 kali pengulangan, maka unit percobaan pada penelitian ini adalah 9 unit percobaan. Dengan tujuan untuk mengetahui kesukaan panelis dengan uji organoleptik, ,kadar air, kadar anu dan kadar vitamin $\mathrm{C}$ dodol salak.

\section{Prosedur Kerja}

1. Alat dan bahan disiapkan.

2. Buah salak disortasi.

3. Buah salak dikupas dan dipisahkan dari bijinya.

4. Semua bahan dicuci.

5. Semua bahan yang telah disiapkan ditimbang.

6. Salak direbus selama 30 menit hingga lunak.

7. Buah salak kemudian dihaluskan dengan cara di blender.

8. Santan dimasak selama 5 menit hingga mengeluarkan minyak lalu tambahkan gula merah, gula pasir, kayu manis, garam dan vanili dan diaduk dengan api yang kecil.

9. Buah salak yang sudah dihaluskan dimasukkan ke campuran santan yang telah dimasak.

10. Adonan dodol diaduk hingga mengental selama 35 menit.

11. Tepung beras dan tepung beras ketan ditambahkan sedikit demi sedikit agar adonan dodol mengeras dan minyak ditambahkan ke dalam adonan dodol agar mempermudah proses pengadukan.

12. Dodol diaduk kembali selama 15 menit agar tidak gosong.

13. Dodol didinginkan selama 30 menit agar mudah dibentuk.

14. Dodol dikemas menggunakan plastik dan dimasukkan kedalam toples.
15. Diuji kadar air, kadar abu, kadar vitamin $C$ dan organoleptik terhadap warna, aroma, rasa dan tekstur.

E. Parameter yang Diuji

1. Uji Organoleptik

a) Warna

Warna merupakan kesan pertama yang muncul dan dinilai oleh panelis. Menurut Winarno (1997) warna merupakan parameter organoleptik yang paling pertama dalam penyajian. Warna merupakan kesan pertama karena menggunakan indera penglihatan. Warna yang menarik akan mengundang selera panelis atau konsumen untuk mencicipi produk tersebut.

\section{b) Aroma}

Menurut Lamusu (2018), bahwa aroma yang disebarkan oleh makanan merupakan daya tarik yang sangat kuat dan mampu merangsang indera penciuman sehingga membangkitkan selera. Timbulnya aroma makanan disebabkan oleh terbentuknya senyawa yang mudah menguap sebagai akibat atau reaksi karena pekerjaan enzim atau dapat juga terbentuk tanpa bantuan reaksi enzim. Kemudian komponen aroma sangat berkaitan dengan konsentrasi komponen aroma tersebut dalam fase uap di dalam mulut. Konsentrasi ini juga dipengaruhi oleh sifat volati dari aroma itu sendiri. Faktor lain adalah interaksi alami antara komponen aroma dan komponen nutrisi dalam makan tersebut seperti karbohidrat, protein dan lemak serta penerimaan konsumen yang sangat relatif.

c) Tekstur

Tekstur ciri suatu bahan sebagai akibat perpaduan dari berbagai sifat fisik yang meliputi ukuran, bentuk, jumlah dan unsur-unsur pembentukan bahan yang dirasakan oleh indera peraba dan perasa, termasuk indera mulut dan penglihatan. Tekstur makanan merupakan bentuk rangsangan fisik ketika terjadi kontak antara bagian dalam rongga mulut dan makanan. Tekstur dari suatu produk makanan mencakup kekentalan, cairan, semi solid dan padatan. Salah satu faktor yang menentukan kualitas makanan adalah kandungan senyawa cita rasa. Senyawa cita rasa ini merupakan senyawa yang menyebabkan timbulnya sensasi rasa manis, pahit, asam dan asin (Tarwendah, 2017).

d) Rasa

Rasa merupakan unsur yang penting dalam menentukan penerimaan konsumen terhadap suatu produk pangan dan merupakan faktor yang mempengaruhi cita rasa makanan setelah penampilan makanan itu sendiri (Moehyi,1992). 
2. Kadar Air ( AOAC, 2005)

a) Cawan porselin dikeringkan dalam oven terlebih dahulu selama 15 menit.

b) Didinginkan dalam desikator selama 20 menit lalu berat cawan ditimbang dan dicatat.

c) Kemudian ditambahkan sampel sebanyak 2 gram.

d) Setelah itu sampel dalam cawan dikeringkan didalam oven dengan suhu $105^{\circ} \mathrm{C}$ selama 3 jam.

e) Lalu didinginkan dalam desikator selama 15 menit.

f) Kemudian cawan dan bahan didalamnya ditimbang dan catat hasilnya.

g) Setelah itu dikeringkan dalam oven kembali hingga diperoleh berat konstan atau tetap.

h) Perhitungan kadar air dengan rumus sebagai berikut :

Kadar air $(\%) \frac{(\mathrm{W} 1+\mathrm{W} 2)-\mathrm{W} 3}{\mathrm{~W} 2} \times 100 \%$

Keterangan :

$\mathrm{W} 1=$ Berat cawan gram.

$\mathrm{W} 2=$ Berat sampel gram.

$\mathrm{W} 3$ = berat cawan dan sampel

setelah dikeringkan gram.

3. Kadar Abu (AOAC, 2005)

a) Disiapkan alat dan bahan yang digunakan.

b) Cawan porselin dikeringkan dalam oven pada suhu $100-105^{\circ} \mathrm{C}$ selama 30 menit.

c) Cawan diangkat menggunakan penjepit cawan, lalu dinginkan dalam desikator selama 20 menit, kemudian ditimbang berat cawan kosong menggunakan neraca analitik.

d) Sampel dimasukkan ke cawan dengan cepat sebanyak \pm 2 gram dan timbang dengan neraca analitik.

e) Cawan ditempatkan kedalam tanur dingin menggunakan gegep dan sarung tangan.

f) Pengabuan dilakukan dua tahap yaitu pemanas pada suhu $300^{\circ} \mathrm{C}$ agar kandungan bahan volatil dan lemak terlindungi hingga kandungan asam hilang, pemanasan dilakukan hingga asam habis. Pemanasan pada suhu $550^{\circ} \mathrm{C}$, pemanasan tahap

g) pertama bertujuan agar suhu secara tiba-tiba tidak perubahan menyebabkan cawan pecah.

h) Tanur dimatikan dan tunggu sampai suhu paling tidak suhu $250^{\circ} \mathrm{C}$, atau suhu rendah. Tanur dibuka secara hati-hati untuk mencegah kehilangan abu yang koefisien sangat halus/ringan.

i) Cawan diangkat menggunakan penjepit cawan dan dipindahkan ke desikator secara cepat ditutup dan dibiarkan dingin selama \pm 1 jam, setelah itu timbang berat konstan/berat cawan dan abu setelah proses pengabuan.

j) Perhitungan kadar abu dengan menggunakan rumus sebagai berikut :

Kadar abu $\%=\frac{B 2-B 1}{B} \times 100 \%$

Keterangan :
$\mathrm{B}=$ berat sampel gram.

$\mathrm{B} 1=$ berat cawan gram.

$\mathrm{B} 2$ = berat cawan + sampel akhir gram

4. Uji Vitamin C

a) Dimasukkan $10 \mathrm{~mL}$ ekstrak sampel kedalam erlenmeyer.

b) Ditambahkan 2 tetes larutan amilum pada erlenmeyer.

c) Ditambahkan $20 \mathrm{~mL}$ akuades kedalam erlenmeyer.

d) Dititrasikan larutan iodium perlahan-lahan.

e) Digoyangkan gelas erlenmeyer setiap tetesan agar merata.

f) Dihentikan titrasi saat larutan berubah warna menjadi biru.

g) Dihitung jumlah iodium (dalam $\mathrm{ml}$ ) yang telah dititrasikan.

Kadar vitamin $\mathrm{C}$ dapat ditentukan secara titrasi dengan menggunakan larutan Iodin $0,01 \mathrm{~N}$, dimana $1 \mathrm{ml}$ larutan iodin $0,01 \mathrm{~N}=0,88 \mathrm{mg}$ asam askorbat (Rahman dkk., 1989)

\section{A. Uji Organoleptik}

\section{HASIL DAN PEMBAHASAN}

1. Warna

Peranan warna sangat penting dalam bahan pangan karena memberikan kesan pertama karena menggunakan indera penglihatan. Warna yang menarik akan mengundang selera panelis atau konsumen untuk mencicipi produk tersebut. Hasil penelitian terhadap rata-rata tingkat kesukaan panelis terhadap warna dodol salak dapat dilihat pada tabel berikut :

Tabel 1. Rata-Rata Tingkat Kesukaan Warna Terhadap Dodol Salak.

\begin{tabular}{llllll}
\hline \multirow{2}{*}{ Perlakuan } & \multicolumn{2}{l}{ Ulangan } & Jumlah & $\begin{array}{l}\text { Rata- } \\
\text { rata }\end{array}$ \\
\cline { 2 - 4 } & $\mathrm{U} 1$ & $\mathrm{U} 2$ & $\mathrm{U} 3$ & & 3,59 \\
\hline P1 & 3,6 & 3,64 & 3,52 & 10,76 & 3,59 \\
P2 & 3,44 & 3,52 & 3,76 & 10,72 & 3,57 \\
P3 & 3,72 & 3,40 & 3,08 & 10,20 & 3,40 \\
\hline Jumlah & 10,76 & 10,56 & 10,36 & 31,68 & 10,56 \\
\hline
\end{tabular}

Sumber: Data primer setelah diolah, 2021

Keterangan :

$\mathrm{P} 1=$ Salak $750 \mathrm{~g}$ dan tepung beras ketan $250 \mathrm{~g}$.

$\mathrm{P} 2=$ Salak $500 \mathrm{~g}$ dan tepung beras ketan $500 \mathrm{~g}$.

$\mathrm{P} 3=$ Salak $250 \mathrm{~g}$ dan tepung beras ketan $750 \mathrm{~g}$.

Adapun penyajian data dalam bentuk grafik, dapat dilihat pada gambar 1 sebagai berikut : 


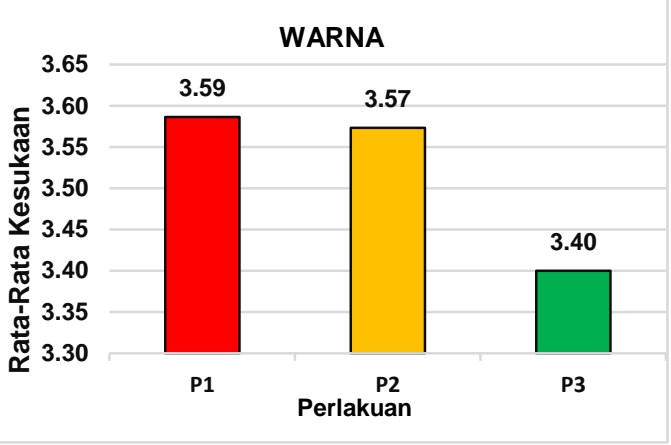

Sumber : Data primer setelah diolah, 2021

Kesukaan panelis terhadap uji organoleptik warna dodol salak yaitu berkisar 3,40-3,59 yang berarti agak suka. Dari hasil tabel dan grafik diatas menunjukkan pada P1 (salak $750 \mathrm{~g}$ dan tepung beras ketan $250 \mathrm{~g}$ ), kemudian tingkat kesukaan pada P2 (salak $500 \mathrm{~g}$ dan tepung beras ketan $500 \mathrm{~g}$ ) dan tingkat kesukaan selanjutnya pada P3 (salak $250 \mathrm{~g}$ dan tepung beras ketan $750 \mathrm{~g}$ ). Maka, tingkat kesukaan panelis uji organoleptik warna pada P1 yaitu 3,59, P2 3,57 dan P3 3,40. Hal ini menjelaskan semakin banyak penambahan salak maka warna dodol yang dihasilkan akan menjadi lebih menarik. Dan warna dodol yang dihasilkan yaitu warna cokelat. Menurut Breemer dkk., (2010), warna cokelat merupakan suatu proses reaksi browning melalui reaksi mailard dan karamelisasi. Pada reaksi mailard yaitu jika gula reduksi dipanaskan, sedangkan pada karamelisasi yaitu jika gula dipanaskan diatas titik lelehnya dan berubah warna menjadi cokelat disertai dengan dengan penambahan cita rasa.

\section{Aroma}

Aroma yang menarik akan mengundang selera panelis atau konsumen untuk mencicipi produk tersebut. Aroma juga merupakan salah satu komponen cita rasa makanan dan dapat menjadi penentu kelezatan makanan. Hasil penelitian rata-rata tingkat kesukaan panelis terhadap aroma dodol salak dapat dilihat pada tabel 2 berikut :

Tabel 2. Rata-Rata Uji Organoleptik Aroma

\begin{tabular}{|c|c|c|c|c|c|}
\hline \multirow{2}{*}{ Perlakuan } & \multicolumn{3}{|c|}{ Ulangan } & \multirow{2}{*}{ Jumlah } & \multirow{2}{*}{$\begin{array}{r}\text { Rata- } \\
\text { rata }\end{array}$} \\
\hline & U1 & U2 & U3 & & \\
\hline P1 & 3,32 & 3,40 & 3,32 & 10,04 & 3,35 \\
\hline $\mathrm{P} 2$ & 3,08 & 3,44 & 3,52 & 10,04 & 3,35 \\
\hline P3 & 3,52 & 3,32 & 3,48 & 10,32 & 3,44 \\
\hline Jumlah & 9,92 & 10,16 & 10,32 & 30,40 & 10,13 \\
\hline
\end{tabular}

Sumber: Data primer setelah diolah, 2021

Keterangan :

$\mathrm{P} 1=$ Salak $750 \mathrm{~g}$ dan tepung beras ketan $250 \mathrm{~g}$.

$\mathrm{P} 2=$ Salak $500 \mathrm{~g}$ dan tepung beras ketan $500 \mathrm{~g}$.

$\mathrm{P} 3=$ Salak $250 \mathrm{~g}$ dan tepung beras ketan $750 \mathrm{~g}$.
Adapun penyajian data dalam bentuk grafik, dapat dilihat pada gambar 2 sebagai berikut :

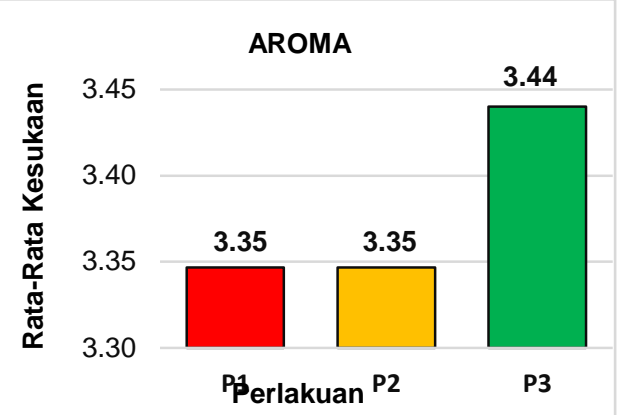

Gambar 2. Grafik Rata-Rata Tingkat Kesukaan Aroma Terhadap Dodol Salak

Kesukaan panelis terhadap uji organoleptik aroma dodol salak yaitu berkisar 3,35-3,44 yang berarti agak suka. Dari hasil tabel dan grafik diatas menunjukkan bahwa pada P1 (salak $750 \mathrm{~g}$ dan tepung beras ketan $250 \mathrm{~g}$ ), kemudian tingkat kesukaan panelis pada P2 (salak $500 \mathrm{~g}$ dan tepung beras ketan $500 \mathrm{~g}$ ) dan tingkat kesukaan panelis selanjutnya pada P3 (salak $250 \mathrm{~g}$ dan tepung beras ketan $750 \mathrm{~g}$ ). Maka, tingkat kesukaan panelis uji organoleptik aroma P1 yaitu 3,35, P2 3,35 dan P3 3,44 . Semakin tinggi nilai rata-rata aroma dodol maka semakin disukai oleh panelis. Hal ini dikarenakan kurangnya penambahan salak dan cukup banyak penambahan tepung beras ketan yang digunakan dalam pembuatan dodol sehingga didapatkan aroma salak yang tidak dominan. Dari hasil yang diketahui dalam pembuatan dodol banyak komponen yang tercampur seperti tepung beras ketan, tepung beras, gula merah dan lain-lain yang dapat mengurangi aroma dodol.

\section{Tekstur}

Tekstur yang menarik akan mengundang selera panelis atau konsumen untuk mencicipi produk tersebut dan tekstur merupakan hal yang harus disesuaikan dengan jenis suatu produk. Hasil penelitian terhadap rata-rata kesukaan tekstur terhadap dodol salak dapat dilihat pada tabel 3 berikut :

Tabel 3. Rata-Rata Tingkat Kesukaan Tekstur Terhadap Dodol Salak.

Sumber : Data primer setelah diolah, 2021

\section{Keterangan :}

$\mathrm{P} 1=$ Salak $750 \mathrm{~g}$ dan tepung beras ketan $250 \mathrm{~g}$.

$\mathrm{P} 2=$ Salak $500 \mathrm{~g}$ dan tepung beras ketan $500 \mathrm{~g}$.

$\mathrm{P} 3=$ Salak $250 \mathrm{~g}$ dan tepung beras ketan 750 g.

Adapun penyajian data dalam bentuk grafik, dapat dilihat pada gambar 3 sebagai berikut : 


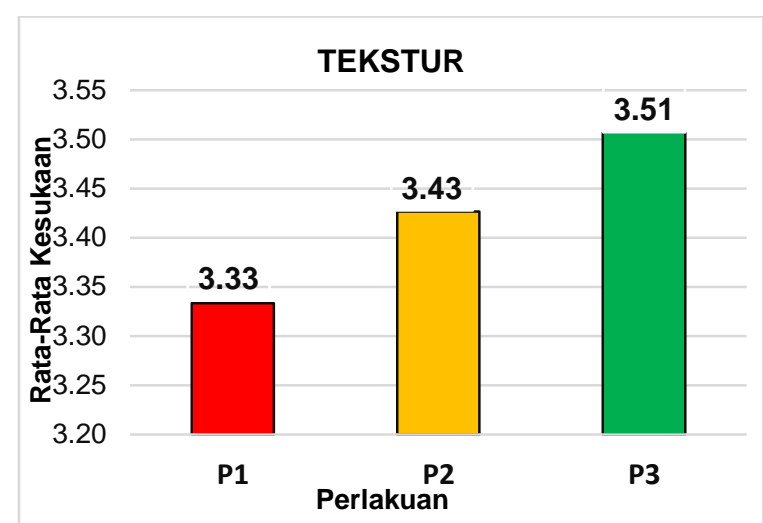

Gambar 3. Grafik Rata-Rata Tingkat Kesukaan Tekstur Terhadap Dodol Salak.

Rata-rata tingkat kesukaan panelis terhadap uji organoleptik tekstur dodol salak yaitu berkisar 3,33-3,51 yang berarti agak suka. Dari hasil tabel dan grafik diatas menunjukkan bahwa pada P1 (salak $750 \mathrm{~g}$ dan tepung beras ketan $250 \mathrm{~g}$ ), kemudian tingkat kesukaan panelis pada P2 (salak $500 \mathrm{~g}$ dan tepung beras ketan $500 \mathrm{~g}$ ) dan tingkat kesukaan panelis selanjutnya pada P3 (salak $250 \mathrm{~g}$ dan tepung beras ketan $750 \mathrm{~g}$ ). Maka, tingkat kesukaan panelis uji organoleptik tekstur dodol salak pada P1 yaitu 3,33, P2 3,43 dan P3 3,51, semakin tinggi nilai ratarata tekstur dodol maka semakin disukai oleh panelis. Hal ini menunjukkan bahwa kurangnya penambahan salak dan cukup banyak penambahan tepung beras ketan yang digunakan dalam pembuatan dodol sehingga didapatkan tekstur salak yang agak kenyal. Hal ini di sebabkan karena adanya penambahan tepung beras ketan pada dodol salak. Menurut Haryadi (2006), komponen utama dodol ialah tepung beras ketan, karena pada saat pemanasan dengan keberadaan cukup banyak air, pati yang terkandung dalam tepung menyerap air dan membentuk pasta yang kental dan pada saat dingin akan membentuk tekstur yang kenyal.

Lestari dkk (2013) menyatakan penggunaan tepung beras ketan pada pembuatan dodol akan menjadikan dodol dengan tekstur yang terlalu liat. Hal ini diakibatkan karena kandungan amilopektin pada tepung beras ketan yang tinggi yaitu sebesar $98 \%$ sehingga mengakibatkan viskositas yang tinggi dan membentuk tekstur dodol menjadi liat. Selain adanya amilopektin, amilosja juga berperan dalam pembentukan tekstur dodol, amilosa akan memberikan tekstur keras dan kering, sehingga apabila kandungan amilosa terlalu tinggi akan membentuk tekstur keras pada produk dodol.

\section{Rasa}

Rasa merupakan salah satu hal terpenting pada makanan. Rasa sangat mempengaruhi kesukaan panelis terhadap dodol salak. Jika rasa yang dihasilkan dodol salak tidak sesuai dengan yang diharapkan panelis maka, panelis akan tidak suka terhadap dodol salak tersebut. Hasil penelitian terhadap rata-rata kesukaan rasa terhadap dodol salak dapat dilihat pada tabel 4 berikut ini :

\begin{tabular}{cccccc}
\hline \multirow{2}{*}{ Perlakuan } & \multicolumn{3}{c}{ Ulangan } & Jumlah & $\begin{array}{c}\text { Rata- } \\
\text { rata(\%) }\end{array}$ \\
\cline { 2 - 4 } & $\mathrm{U} 1$ & $\mathrm{U} 2$ & $\mathrm{U} 3$ & & 24,23 \\
P1 & 25,38 & 24,02 & 23,29 & 72,69 & 23,03 \\
P2 & 19,21 & 17,97 & 16,92 & 54,10 & 18,03 \\
P3 & 17,78 & 18,38 & 17,10 & 53,26 & 17,75 \\
Jumlah & 62,38 & 60,36 & 57,31 & 180,05 & 60,02 \\
\hline
\end{tabular}

Tabel 4. Rata-Rata Tingkat Kesukaan Rasa Terhadap Dodol Salak

Sumber: Data primer setelah diolah, 2021

Keterangan :

$\mathrm{P} 1=$ Salak $750 \mathrm{~g}$ dan tepung beras ketan $250 \mathrm{~g}$.

$\mathrm{P} 2=$ Salak $500 \mathrm{~g}$ dan tepung beras ketan $500 \mathrm{~g}$.

$\mathrm{P} 3=$ Salak $250 \mathrm{~g}$ dan tepung beras ketan $750 \mathrm{~g}$.

Adapun penyajian data dalam bentuk grafik, dapat dilihat pada gambar 4 sebagai berikut :

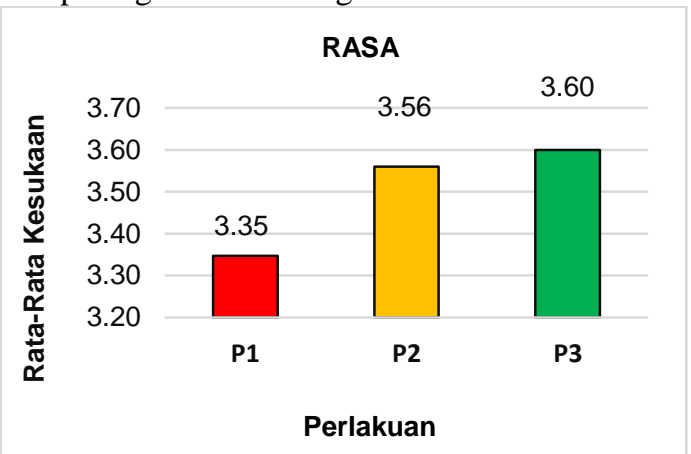

Gambar 4. Grafik Rata-Rata Tingkat Kesukaan Rasa Terhadap Dodol Salak.

Rata-rata tingkat kesukaan panelis terhadap uji organoleptik rasa dodol salak yaitu berkisar 3,35-3,60 yang berarti agak suka. Dari hasil tabel dan grafik diatas menunjukkan bahwa pada P1 (salak $750 \mathrm{~g}$ dan tepung beras ketan $250 \mathrm{~g}$ ), kemudian tingkat kesukaan panelis pada P2 (salak $500 \mathrm{~g}$ dan tepung beras ketan $500 \mathrm{~g}$ ) dan tingkat kesukaan panelis selanjutnya pada P3 (salak $250 \mathrm{~g}$ dan tepung beras ketan $750 \mathrm{~g}$ ). Maka, tingkat kesukaan panelis uji organoleptik P1 yaitu 3,35, P2 3,56 dan P3 3,60, semakin tinggi nilai rata-rata tekstur dodol maka semakin disukai oleh panelis. Maka, kurangnya penambahan salak yang membuat rasa salak pada dodol kurang dominan. Dengan rasa kita bisa menilai suatu masakan itu apakah enak, tidak enak, manis, asin atau pahit.

\section{B. Kadar Air}

Kadar air dapat menyebabkan terjadinya reaksi-reaksi yang dapat menurunkan mutu suatu bahan, sehingga bahan dapat dengan mudah rusak dan tidak tahan lama. Oleh karena itu, untuk 
memperpanjang daya tahan terhadap serangga mikroorganisme dan penyimpanan, maka air pada bahan dihilangkan. Oleh karena itu hasil penelitian kadar air terhadap dodol salak dapat dilihat pada tabel 5 .

\begin{tabular}{cccccc}
\hline \multirow{2}{*}{ Perlakuan } & \multicolumn{3}{c}{ Ulangan } & Jumlah & $\begin{array}{c}\text { Rata- } \\
\text { rata }\end{array}$ \\
\cline { 2 - 4 } & $\mathrm{U} 1$ & $\mathrm{U} 2$ & $\mathrm{U} 3$ & & 10,04 \\
\hline P1 & 3,44 & 3,12 & 3,48 & 3,35 \\
P2 & 3,32 & 3,60 & 3,76 & 10,68 & 3,56 \\
P3 & 3,68 & 3,72 & 3,40 & 10,80 & 3,60 \\
\hline Jumlah & 10,44 & 10,44 & 10,64 & 31,52 & 10,51 \\
\hline
\end{tabular}

Tabel 5. Rata-Rata Kadar Air Dodol Salak

Sumber: Data primer setelah diolah, 2021

\section{Keterangan :}

$\mathrm{P} 1=$ Salak $750 \mathrm{~g}$ dan tepung beras ketan $250 \mathrm{~g}$.

$\mathrm{P} 2=$ Salak $500 \mathrm{~g}$ dan tepung beras ketan $500 \mathrm{~g}$.

$\mathrm{P} 3=$ Salak $250 \mathrm{~g}$ dan tepung beras ketan $750 \mathrm{~g}$.

Adapun penyajian data dalam bentuk grafik, dapat dilihat pada gambar 5 sebagai berikut :

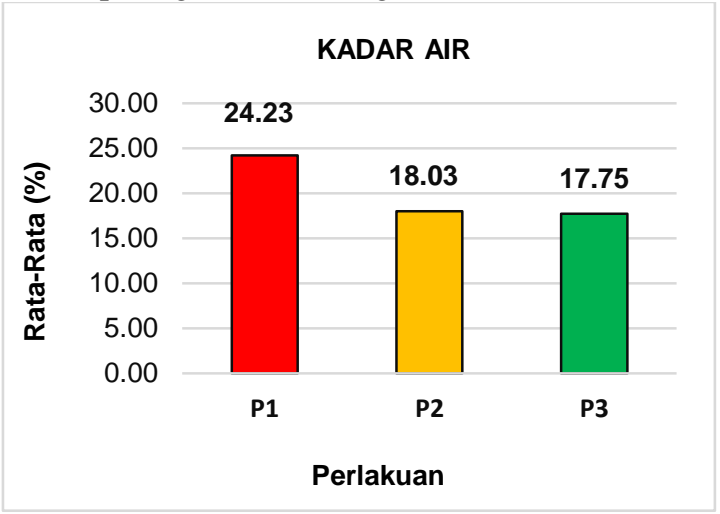

Gambar 5. Grafik Rata-Rata Kadar Air Terhadap Dodol Salak.

Hasil tabel 5 dan gambar 5 menunjukkan bahwa kadar air terhadap dodol salak pada P1 (salak $750 \mathrm{~g}$ dan tepung beras ketan $250 \mathrm{~g}$ ) dengan kadar air sebesar $24,23 \%$, kemudian pada P2 (salak $500 \mathrm{~g}$ dan tepung beras ketan $500 \mathrm{~g}$ ) dengan kadar air sebesar 18,03\% dan pada P3 (salak sebanyak $250 \mathrm{~g}$ dan tepung beras ketan $750 \mathrm{~g}$ ) dengan kadar air $17,75 \%$. Kadar air pada setiap perlakuan masih ada yang belum memenuhi persyaratan SNI dodol yaitu memiliki kadar air dibawah $20 \%$. Pada P1 memiliki kadar air yang tinggi dikarenakan penambahan salak di P1 cukup banyak yaitu $750 \mathrm{~g}$ dengan tepung beras ketan yang sedikit yaitu 250 g. Salak mempunyai kandungan air yang tinggi, maka dari itu semakin banyak salak yangditambahkan dalam proses pembuatan dodol maka kadar air yang dihasilkan akan tinggi. Tujuan kadar air adalah untuk mengetahui jumlah air yang terdapat dalam produk akhir yang dihasilkan. Semakin banyak kadar air yang terkandung dalam suatu bahan maka akan mengakibatkan penurunan kualitas terhadap produk. Hal ini diperkuat oleh
(Winarno, 1997) yang menyatakan bahwa kadar air dalam bahan pangan ikut menentukan kesegaran dan daya awet bahan pangan tersebut, kadar air yang tinggi mengakibatkan mudahnya bakteri, kapang dan kamir untuk berkembang biak, sehingga akan terjadi perubahan pada bahan pangan.

C. Kadar Abu

Analisis kadar abu pada bahan makanan bertujuan untuk mengetahui kandungan mineral yang ada pada bahan yang diuji, menentukan baik tidaknya suatu proses pengolahan, mengetahui jenis bahan yang digunakan, memperkirakan kandungan bahan utama yang digunakan dalam pembuatan suatu produk, kadar abu juga digunakan sebagai parameter nilai gizi bahan makanan. Hasil penelitian terhadap rata-rata kadar abu terhadap dodol salak dapat dilihat pada tabel 6 .

\begin{tabular}{cccccc}
\hline \multirow{2}{*}{ Perlakuan } & \multicolumn{3}{c}{ Ulangan } & Jumlah & $\begin{array}{c}\text { Rata- } \\
\text { rata(\%) }\end{array}$ \\
\cline { 2 - 4 } & U1 & U2 & U3 & & 1,83 \\
P1 & 1,16 & 1,94 & 2,39 & 5,49 & 1,50 \\
P2 & 0,04 & 1,69 & 2,77 & 4,50 & 0,56 \\
Jumlah & 0,96 & 0,69 & 0,02 & 1,67 & 0,89 \\
\hline
\end{tabular}

Tabel 6. Rata-Rata Kadar Abu Dodol Salak.

Sumber: Data primer setelah diolah, 2021

Keterangan :

$\mathrm{P} 1=$ Salak $750 \mathrm{~g}$ dan tepung beras ketan $250 \mathrm{~g}$.

$\mathrm{P} 2=$ Salak $500 \mathrm{~g}$ dan tepung beras ketan $500 \mathrm{~g}$.

$\mathrm{P} 3=$ Salak $250 \mathrm{~g}$ dan tepung beras ketan $750 \mathrm{~g}$.

Adapun penyajian data dalam bentuk grafik, dapat dilihat pada gambar 6 sebagai berikut :

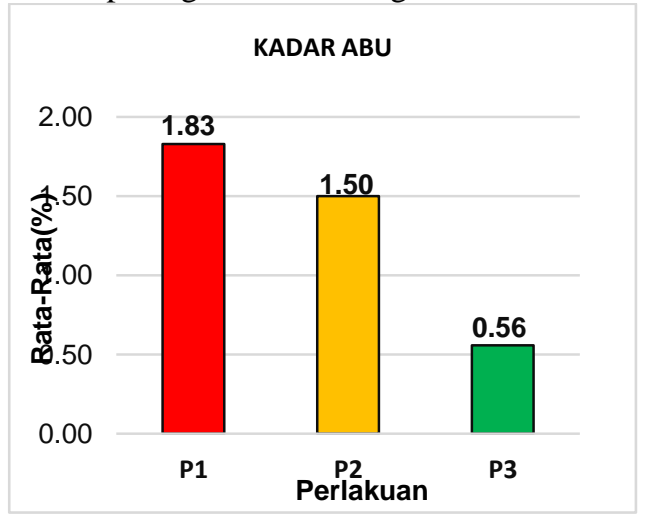

Gambar 6.Grafik Rata-Rata Kadar Abu Terhadap Dodol Salak

Hasil tabel 6 dan gambar 6 menunjukkan bahwa kadar abu terhadap dodol salak setelah pembakaran memberikan nilai pada P1 (salak 750 $\mathrm{g}$ dan tepung beras ketan $250 \mathrm{~g}$ ) menghasilkan kadar abu sebesar 1,83\%, P2 (salak $500 \mathrm{~g}$ dan tepung beras ketan $500 \mathrm{~g}$ ) menghasilkan kadar abu sebesar 1,50\% dan P3 (salak sebanyak $250 \mathrm{~g}$ dan 
tepung beras ketan $750 \mathrm{~g}$ ) menghasilkan kadar abu sebesar $0,56 \%$. Hal tersebut menunjukkan bahwa semakin banyak penambahan salak maka kadar abu yang dihasilkan semakin tinggi. Hal ini diperkuat oleh Supraptiah, dkk., (2015) bahwa kadar abu tergantung pada jenis bahan, cara pengabuan, waktu dan suhu yang digunakan saat pengeringan serta semakin rendah komponen non mineral yang terkandung dalam bahan akan semakin meningkatkan persen abu relatif pada bahan.

\section{Kadar Vitamin C}

Hasil penelitian terhadap rata-rata kadar vitamin $\mathrm{C}$ terhadap dodol salak dapat dilihat pada tabel 7

\begin{tabular}{|c|c|c|c|c|c|c|c|}
\hline \multirow{2}{*}{$\begin{array}{c}\text { Perlakua } \\
\text { n }\end{array}$} & \multicolumn{3}{|c|}{ Ulangan } & \multirow{2}{*}{$\begin{array}{c}\text { Jumla } \\
\mathrm{h}\end{array}$} & \multirow{2}{*}{$\begin{array}{l}\text { Rata } \\
\text {-rata }\end{array}$} & \multirow{2}{*}{$\begin{array}{c}0,88 \\
\text { Vitami } \\
\mathrm{n} \mathrm{C}=1 \\
\text { ml } \\
\text { larutan } \\
\text { iodin } \\
\end{array}$} & \multirow{2}{*}{$\begin{array}{c}\text { Vitami } \\
\mathrm{n} \mathrm{C} \\
\text { Dodol } \\
\text { Salak } \\
(\mathrm{mg} / 10 \\
0 \mathrm{~g}) \\
\end{array}$} \\
\hline & U1 & $\mathrm{U} 2$ & U3 & & & & \\
\hline P1 & $\begin{array}{c}3,9 \\
0\end{array}$ & $\begin{array}{c}3,9 \\
0\end{array}$ & $\begin{array}{c}3,9 \\
0\end{array}$ & 11,70 & 3,90 & 0,88 & 3,43 \\
\hline $\mathrm{P} 2$ & $\begin{array}{c}3,4 \\
0\end{array}$ & $\begin{array}{c}3,4 \\
0\end{array}$ & $\begin{array}{c}3,4 \\
0\end{array}$ & 3,40 & 3,40 & 0,88 & 2,99 \\
\hline P3 & $\begin{array}{c}1,2 \\
0\end{array}$ & $\begin{array}{c}1,2 \\
0\end{array}$ & $\begin{array}{c}1,2 \\
0\end{array}$ & 0,30 & 1,20 & 0,88 & 1,06 \\
\hline Jumlah & $\begin{array}{c}8,5 \\
0\end{array}$ & $\begin{array}{c}8,5 \\
0\end{array}$ & $\begin{array}{c}8,5 \\
0\end{array}$ & 25,50 & 8,50 & 0,88 & 7,48 \\
\hline
\end{tabular}

Tabel 7. Rata-Rata Kadar Vitamin C Dodol Salak Sumber: Data primer setelah diolah, 2021

Keterangan :

$\mathrm{P} 1=$ Salak $750 \mathrm{~g}$ dan tepung beras ketan $250 \mathrm{~g}$.

$\mathrm{P} 2=$ Salak $500 \mathrm{~g}$ dan tepung beras ketan $500 \mathrm{~g}$.

$\mathrm{P} 3=$ Salak $250 \mathrm{~g}$ dan tepung beras ketan $750 \mathrm{~g}$.

Adapun penyajian data dalam bentuk grafik, dapat dilihat pada gambar 7 sebagai berikut :

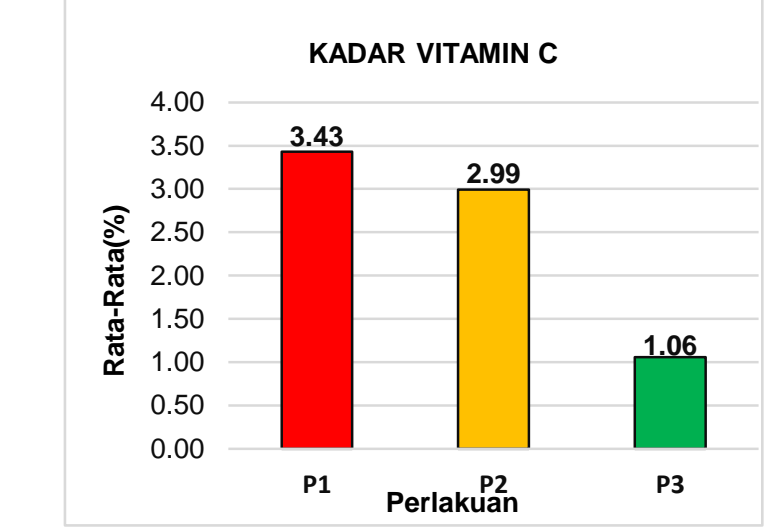

Gambar 7. Grafik Rata-Rata Vitamin C Terhadap Dodol Salak

Hasil tabel 7 dan gambar 7 menunjukkan bahwa kadar vitamin $\mathrm{C}$ terhadap dodol salak pada P1 (salak $750 \mathrm{~g}$ dan tepung beras ketan $250 \mathrm{~g}$ ) menghasilkan kadar vitamin $\mathrm{C}$ sebesar 3,43 $\mathrm{mg} / 100 \mathrm{~g}$, P2 (salak $500 \mathrm{~g}$ dan tepung beras ketan 500 g) menghasilkan vitamin $C$ sebesar 2,99 $\mathrm{mg} / 100 \mathrm{~g}$ dan P3 (salak $250 \mathrm{~g}$ dan tepung beras ketan 750 g) menghasilkan kadar vitamin C sebesar 1,06 mg/100 g. Dan kandungan vitamin C pada buah salak yaitu $2 \mathrm{mg} / 100 \mathrm{~g}$. Karena kadar vitamin $\mathrm{C}$ yang terdapat pada salak cukup tinggi maka semakin banyak penambahan salak pada dodol salak maka vitamin $\mathrm{C}$ yang dihasilkan juga tinggi. Dodol salak menghasilkan perubahan warna kebiru-biruan setelah ditetesi larutan iodin dikarenakan tepung beras ketan dan tepung beras yang digunakan pada proses pembuatan dodol salak mengandung pati. Pati adalah karbohidrat yang merupakan polimer glukosa, yang terdiri dari amilosa dan amilopektin. Sementara itu, amilosa menghasilkan warna biru bila ditetesi larutan iodin, sedangkan amilopektin menghasilkan warna coklat kemerahan (Saragih, 2013).

\section{KESIMPULAN}

- Berdasarkan hasil dari penelitian Studi Pembuatan Dodol Dengan Konsentrasi Penambahan Salak (Salacca zalacca) Yang Berbeda dapat disimpulkan sebagai berikut :

1. Hasil penelitian menunjukkan uji organoleptik terbaik pada warna dodol salak yaitu P1 (Salak $750 \mathrm{~g}$ dan tepung beras ketan $250 \mathrm{~g}$ ) sebesar 3,59 (agak suka). Dari aroma yang terbaik dodol salak yaitu P3 (Salak $250 \mathrm{~g}$ dan tepung beras ketan $750 \mathrm{~g}$ ) sebesar 3,44 (agak suka). Dari tekstur yang terbaik dodol salak yaitu P3 (Salak $250 \mathrm{~g}$ dan tepung beras ketan 750) sebesar 3,51 (agak suka). Dari segi rasa yang terbaik pada dodol salak P3 (Salak $250 \mathrm{~g}$ dan tepung beras ketan $750 \mathrm{~g}$ ) sebesar 3,60 (agak suka).

2. Kadar air dodol salak yang sesuai dengan SNI kadar air dodol maksimal $20 \%$ yaitu pada P3 (Salak $250 \mathrm{~g}$ dan tepung beras ketan $750 \mathrm{~g}$ ) sebesar $17,75 \%$. Kadar abu dodol salak yang sesuai dengan SNI kadar abu dodol maksimal $1,5 \%$ yaitu pada P3 (Salak $250 \mathrm{~g}$ dan tepung beras ketan $750 \mathrm{~g}$ ) sebesar $0,56 \%$ dan kadar vitamin c dodol salak yang tertinggi yaitu pada $\mathrm{P} 1$ sebesar 3,43 mg/100 g.

\section{DAFTAR PUSTAKA}

AOAC. 2005. Official Methods of association of Official Analytical Chemists.12t $\mathrm{H}$ Edition. Published by Association of Official Analytical Chemist. Benjamin Franklin station, Washington.

Breemer, R., Polnaya, F. J., \& Rumahrupute, C. (2010). Pengaruh Konsentrasi Tepung Beras Ketan Terhadap Mutu Dodol Pala. Jurnal Budidaya Pertanian, 6(1), 17-20. 
Haryadi. 2006. Teknologi Pengolahan Beras. Yogyakarta: Gadjah Mada University Press

Lamusu D. (2018). Uji Organoleptik Jalangkote Ubi Jalar Ungu (Ipomoea batatas 1) Sebagai Upaya Diversifikasi Pangan. Jurnal Pengolahan Pangan, 3(1), 9-15.

Lestari, Dewi dkk. (2013). "Pengaruh Subsitusi Tepung Tapioka Terhadap Tekstur dan Nilai Uji Organoleptik Dodol Susu". Jurnal Fakultas Peternakan.

Moehyi, S. 1992. Penyelenggaraan Makanan Institusi dan Jasa Boga. Penerbit Bharata. Jakarta.

Rahman, N., Ofika, M., \& Said, I. (2015). Analisis Kadar Vitamin C Mangga Gadung (Mangifera sp) dan Mangga Golek (Mangifera Indica L) Berdasarkan Tingkat Kematangan Dengan Menggunakan Metode Iodimetri. Jurnal Akademika Kimia, 4(1), 33-3

Supraptiah, E. (2019). Optimasi Temperatur dan Waktu Pengeringan Mie Kering Yang Berbahan Baku Tepung Jagung Dan Tepung Terigu. Kinetika, 10(2), 42-47.

Saragih, B. (2013). Analisis Mutu Tepung Bonggol Pisang Dari Berbagai Varietas dan Umur Panen Yang Berbeda. Jurnal TIBBS Teknologi Industri Boga dan Busana, 9(1), 22-29.

Tarwendah, I. P. (2017). Studi Komparasi Atribut Sensoris dan Kesadaran Merek Produk Pangan. Jurnal Pangan dan Agroindustri, 5(2). 